Sharif University of Technology
Scientia Iranica
Transactions E: Industrial Engineering
hCIENTIA

\title{
Robust parameter design of supply chain inventory policy considering the uncertainty of demand and lead time
}

\author{
L.N. Tang ${ }^{\mathrm{a}}$, Y.Z. Ma ${ }^{\mathrm{a}}$, J.J. Wang ${ }^{\mathrm{a}}{ }^{*}$, L.H. Ouyang ${ }^{\mathrm{b}}$, and J.H. Byun ${ }^{\mathrm{c}}$ \\ a. School of Economics and Management, Nanjing University of Science and Technology, Nanjing, Jiangsu 210094, China. \\ b. College of Economics and Management, Nanjing University of Aeronautics and Astronautics, Nanjing, Jiangsu, 211106, China. \\ c. Department of Industrial and System Engineering, Gyeongsang National University, 501 Jinju-daero, Jinju, 660-701, Korea.
}

Received 9 October 2017; received in revised form 8 March 2018; accepted 14 May 2018

\section{KEYWORDS \\ Supply chain; Inventory policy; Simulation; \\ Taguchi method; \\ Response surface methodology.}

\begin{abstract}
The uncertainty of demand and lead time in inventory management has posed challenges for the supply chain management. The purpose of this paper is to optimize the total profit and customer service level of supply chain by robust parameter design of inventory policies. This paper proposes system dynamics simulation, Taguchi method, and Response Surface Methodology (RSM) to model a multi-echelon supply chain. Based on the sequential experiment principle, Taguchi method combining location with dispersion modeling method is adopted to locate the optimum area quickly, which is very efficient to optimize the responses at discrete levels of parameters. Then, fractional factorial design and full factorial design are used to recognize significant factors. Finally, RSM is used to find the optimal combinations of factors for profit maximization and customer service level maximization at continuous levels of parameters. Furthermore, a discussion of multiresponse optimization is addressed with different weights of each response. Confirmation experiment results showed the effectiveness of the proposed method.
\end{abstract} C 2019 Sharif University of Technology. All rights reserved.

\section{Introduction}

\subsection{Supply chain simulation}

During the last few decades, supply chain analysis has become a major concern both in manufacturing theory and in industrial practice. In the extended sense, which is now prevailing in the literature, a supply chain is associated with all the enterprises that contribute to the production and sales of products (goods or services). Several performance indices have been proposed to evaluate the quality of a supply chain,

\footnotetext{
*. Corresponding author.

E-mail address: jjwang@njust.edu.cn (J.J. Wang)
}

particularly in terms of costs and value, decisional integration, agility, reactivity, and reliability [1].

Using computer simulation to study the supply chain optimization problems has become a new trend in recent years. Many scholars use computer simulation to obtain reliable data for the analysis of a supply chain model. Simulation is used to model a system or a process, giving support to decision-making that enables the reduction of risks and costs involved in a process; it becomes a tool for a process optimization. It is also important to model the interaction among the various participants precisely. Both the planning and performance of activities should be considered. To be specific, the typical activities include the management of stock as well as production and delivery of final products. The performance of each participant of the 
supply chain has impact on the performance of all other participants. Hence, the importance of coordinating the actions of various participants of the supply chain should be taken into account $[2,3]$.

Simulation, specifically discrete event simulation, is an important tool in the analysis and evaluation of a supply chain. A two-echelon supply chain model is adopted widely to study the inventory control and network design of the supply chain [4-6]. The multiechelon supply chain model (including factory, wholesaler, distributor, and retailer) is studied to further investigate the design problems in a complex supply chain network [2,3,7-14]. One popular and classic multi-echelon supply chain model is known as "Beer Game" [15]. Shang et al. [16] selected Arena as their working simulation environment to model a three-stage supply chain with four retailers, one manufacturer, and three suppliers. Shi et al. [17] also used Arena software to support the process-centric modeling paradigm for the 3PL-MRCD supply chain. Other variant versions of Beer Game models have been widely used in researches of supply chain management and optimization $[8,9,11]$. Thus, Arena is selected as the simulation environment for the supply chain simulation model in this paper.

\subsection{Robust parameter design}

Robust Parameter Design (RPD) is an engineering methodology intended as a cost-effective approach to the improvement of the quality of products and processes. In the basic assumptions, both controllable factors (control variables) and uncontrollable/difficultto-control factors (noise variables) are involved in the quality characteristic of a process. The goal of parameter design is to optimize a defined quality characteristic by choosing the settings of the control variables, while minimizing the variation imposed on the process via the noise variables. Parameter design was popularized in the mid-1980s by Japanese quality consultant Genichi Taguchi. A panel discussion edited by Nair summarized important responses to Taguchi's ideas and methodology [18]. In the last decade, there have been many applications and new developments in this important area [19].

Design Of Experiment (DOE) [20] has been widely used in the robust parameter design. By selecting the combination levels of the controllable factors to reduce the system sensitivity to noise changes, robust parameter design achieves the objective of reducing the system performance variations. Through a scientific design of experiments, the significant factors that influence the system quality characteristics can be identified. After that, the optimal system outputs can be achieved accordingly so as to optimize the parameter combination design. Box and Wilson [21] first used Response Surface Methodology (RSM) and
Myers and Montgomery [22] extended RSM to robust optimization of real (non-simulated) systems. Taguchi method and response surface method [12,14,17,23,24] have been widely adopted in the robust parameter design problems.

\subsection{Rationale of the research}

Hussain et al. [13] used system dynamics simulation and Taguchi method to quantify the impact of a supply chain's design parameters. According to the Taguchi method, levels of each factor systematically vary across a range of values, and all possible combinations of factor levels (parameter values) are considered, while not every combination has to be tested. Plenty of researches [16,23,25-27] have also applied Taguchi method and Response Surface Methodology (RSM) successfully in the optimization of the supply chain model.

The optimization problem of simulated systems has been tackled by many methods; however, most methods assume known environments. However, this paper adopts a robust parameter design methodology for uncertain environments; the uncertainty mainly comes from demand and lead time. The Beer Game model illustrated in the research of Kumer et al. [15] has the primary inputs and outputs for the Beer Game model. The primary decision or control variables for the Beer Game are the reorder points and reorder quantities. The basic Beer Game simulation only models a single unit at each level in the supply chain, while this paper uses the expanded model that incorporates multiple units at each supply chain level to study the performance of multiple enterprises in the multiechelon supply chain.

This paper uses the Arena simulation software [28] to build Beer Game model for the analysis and optimization of supply chain system. Arena @Rockwell software provides a modular object-oriented development environment. It has a powerful user interface for integration with popular software tools (such as Excel, Visio, VBA, OptQuest, and Crystal Reports). A link to the working Arena simulation model is provided right here: http://factory.engr.stthomas.edu/simula tion. To establish the model, a demonstration copy of Arena software (version 8.0 or later) is required.

The classic Beer Game demonstrates intrinsic capabilities of a simulation tool to facilitate integration of a supply chain with steady-state random demands, inventory management, and lead times encapsulated in the time tested Beer Game. It represents a model that can be scaled up to a larger network of suppliers, Original Equipment Manufacturers (OEMs), etc. with multiple products and other features that replicate complexities in an industry supply chain. In this model, it tracks all inventory levels and their associated costs. Various management scenarios for the supply 
chain management can be studied. The goal of the proposed simulation model is to maximize total profit and Customer Service Level (CSL) of the supply chain. Taguchi method is adopted to find the optimal settings of the decision variables to maximize total profit and customer service level, respectively. Based on the optimization design of decision variables at discrete levels, response surface methodology is used to further optimize the decision variables at continuous levels. The multi-response optimization results are studied under different decision scenarios.

In recent years, many works of literature have focused on the simulation optimization of a supply chain, where the simulation model of the considered supply chain problem is built; then, the sampling method (e.g., Latin Hypercube Sampling (LHS), Monte Carlo) and surrogate modeling method (e.g., RSM, kriging) or other Genetic Algorithms (GA) [7,9,11,27] are applied to analyze and model the simulation model. Other modeling methods include Neural Network (NN) [25], Particle Swarm Optimization (PSO) [27], Simulated Annealing Algorithm (SAA) [7], Hybrid RobustStochastic Programming (HRSP) [10], Ranking and Selection (R\&S) [8], and Integer Linear Programming (ILP) [28]. Table 1 represents a comparative study for a better conclusion on the major work in the literature.

The remainder of this paper is arranged as follows. In Section 2, the methodology proposed in this paper is introduced. A simulation model of the multi-echelon supply chain is demonstrated in Section 3. In Section 4, Taguchi method is used to optimize the total profit and customer service level, respectively. In Section 5, response surface methodology is adopted to explore the optimal settings of inventory policies and reach multi- response optimization. Finally, the results of this paper are summarized in Section 6.

\section{Methodology}

A supply chain should be understood as a set of all the organizations comprising the material (component or product) supply, production, distribution, and selling of goods to the final customer. Managing a supply chain concerns activities that promote functional interactions, both within a single company and amongst distinct ones.

Methods for the supply chain management should be able to simplify possible complexity in a supply chain by adopting a systematic view of the whole chain. Simulation is ideal for mapping these complex interactions and for predicting non-linear outputs through "What If" analysis. Running "What if' simulations to test certain policies or strategies on complex models can greatly aid the understanding of how the system changes over time.

This paper investigates the impact of inventory policy on the performance of a supply chain in a model of the four-echelon supply chain, which suffers from uncertainties in demand and lead time. One of the most commonly applied methodologies to study various aspects of the Beer Game model is the control theoretic technique. It is clear that these control-theoretic models are linear and cannot deal with non-linearities, such as constraints of inventory policies at different levels of supply chain. Robust Parameter Design (RPD) is an innovative statistical/engineering approach to offline quality and productivity improvement. The main idea of RPD is to make a process or product less sen-

Table 1. Summarized comparisons of some major works on simulation optimization.

\begin{tabular}{|c|c|c|c|c|}
\hline Literature & System type & $\begin{array}{l}\text { Multiple } \\
\text { responses }\end{array}$ & $\begin{array}{c}\text { Robust } \\
\text { optimization }\end{array}$ & Modeling method \\
\hline Shang et al. [16] & 4-tier supply chain & $*$ & $*$ & Taguchi, RSM \\
\hline Kumar et al. [15] & 4-tier supply chain & & & OptQuest \\
\hline Shukla et al. [23] & 3 -tier supply chain & $*$ & $*$ & Taguchi, Psychoclonal algorithm \\
\hline Yang et al. [14] & Multi-structure supply chain & $*$ & & Taguchi, MCDM \\
\hline Hussain et al. [13] & 4-tier supply chain & & & Taguchi \\
\hline $\mathrm{Li}$ and Liao [25] & Blood supply chain & & $*$ & Taguchi, NN, GA \\
\hline Shi et al. [12] & Cross docking & $*$ & $*$ & LHS, RSM \\
\hline Chu et al. [11] & 3-tier distribution chain & $*$ & $*$ & $\begin{array}{l}\text { Monte Carlo, } \\
\text { Cutting-plane algorithm, RSM }\end{array}$ \\
\hline Soleimani and Kanaan [27] & Closed loop supply chain network & & $*$ & GA, PSO \\
\hline Rooeinfar et al. [7] & Supply chain network & & & GA, SAA \\
\hline Ye and You [9] & 3-tier supply chain & * & $*$ & Kriging \\
\hline Keyvanshokooh et al. [10] & Closed loop supply chain network & & $*$ & HRSP \\
\hline Tsai and Chen $[8]$ & 3-tier supply chain & $*$ & & $\mathrm{R} \& \mathrm{~S}$ \\
\hline Osorio et al. [28] & Blood supply chain & $*$ & & ILP \\
\hline This paper & 4-tier multi-unit supply chain & $*$ & $*$ & Taguchi, RSM \\
\hline
\end{tabular}


sitive to noise variation through statistically designed experiment by using the non-linearities between input variable and output responses.

Compared with the embedded optimization algorithm [15] in the simulation model, the RPD provides a more strategic way to select the experiment points needed to analyze in order to determine the optimal setting of parameters. This adds more advantages to the RPD method proposed in this paper over other embedded optimization algorithms through its statistical way of experiment design, which makes the proposed methodology in this paper more efficient.

Taguchi method and response surface methodology are two popular RPD approaches. Taguchi method is used to analyze quantitatively the performance of the supply chain with respect to the supply chain's design parameters (control factors). An optimal combination of control factors derived from the optimal supply chain performance can be obtained. However, the selection of optimal setting of factors is limited to the designed levels of their experiment, which are in discrete forms, even though Taguchi method is very effective in finding an appropriate experimental region of factors that can facilitate the following fractional factorial design and RSM optimization.

Response surface methodology is able to find the optimal combination of design parameters derived from the optimal supply chain performance at their continuous levels. According to the sequential principle in the experiment design, a fractional factorial design is first adopted to identify the significant factors that have significant impact on the output responses. Then, full factorial design with centre points is used to check the presence of the curvature (second-order or higherorder effect). If there is no curvature in the experiment region, the steepest descent/ascent method is usually applied to further search for the optimum experiment region. When a significant curvature is recognized, axial points are added to the experiment design matrix in order to analyze the non-linear relations between responses and variables. Finally, the optimal combination of parameters can be obtained to achieve the optimal responses.

The overall framework of the methodology proposed in this paper is presented in Figure 1.

\section{Multi-echelon supply chain model}

In order to study the impact of inventory policy on the performance of the supply chain, a four-echelon supply chain is selected to model the ordering and stocking situation of the supply chain, involving one factory, two wholesalers, four distributors, and eight retailers. The classic simulation case of Beer Game is very popular in the research of supply chain simulation and optimization. The Beer Game simulation

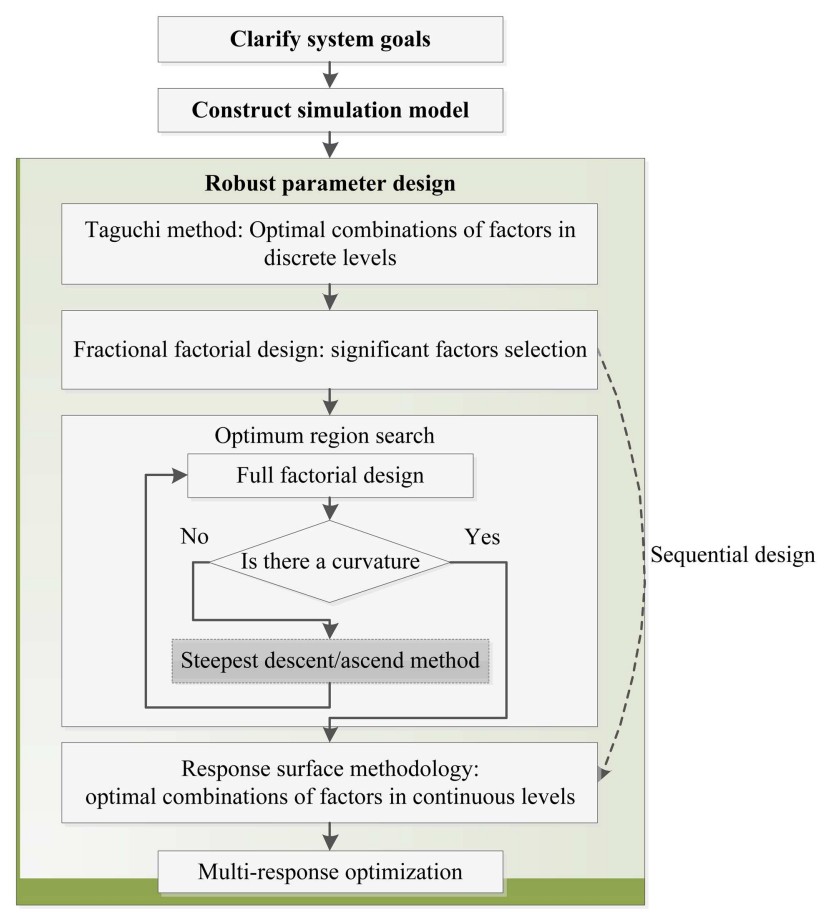

Figure 1. The overall framework of the proposed methodology.

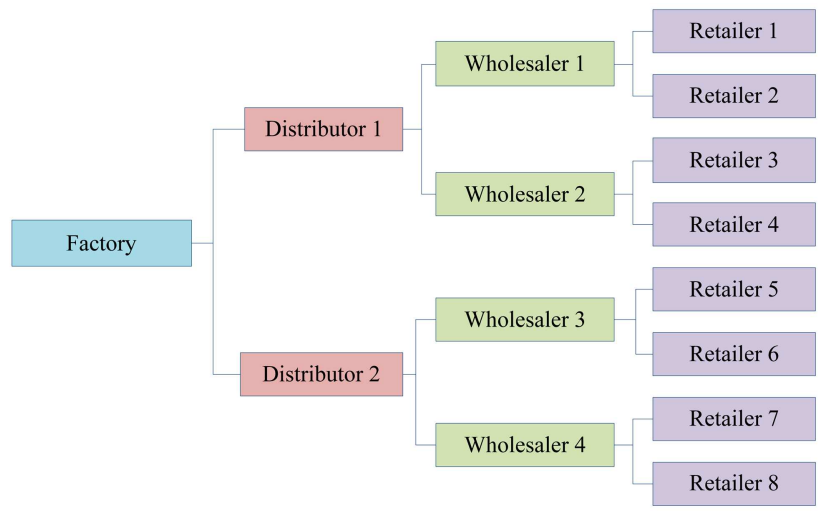

Figure 2. Supply chain structure.

model was originally developed in the 1960s at the Massachusetts Institute of Technology's (MIT) Sloan School of Management. Beer Game is a role-play game to demonstrate the decision-making of supply chain managers. In this paper, a variant of the popular Beer Game is adopted, where each upstream supplier has two downstream customer companies (shown in Figure 2).

Beer Game uses Arena simulation software to model the specific structure of the proposed supply chain model, which reflects the transmission of information flows and material flows in the supply chain. Arena software has a very helpful tool Process Analyzer to study the specified responses under different combinations of control variables, which can derive the 
experimental data for the robust parameter design in the following study.

\subsection{Simulation logic of Beer Game}

The four-echelon supply chain structure is shown in Figure 2. In the proposed supply chain model, order information transmits from customers to retailers. Then, retailers order up to fulfill their inventory from upstream companies. Distributors and wholesalers also order up to fulfill their inventory from upstream. After receiving orders from wholesalers, the factory sets up its production line. In the meanwhile, products are transferred from the factory to downstream and, finally, to customers. The transmission of information flows (Orders) and material flows (Products) in the supply chain is shown in Figure 3.

The simulation system of the supply chain illustrated in Figure 4 shows the primary inputs and outputs in the Beer Game model. The primary decision

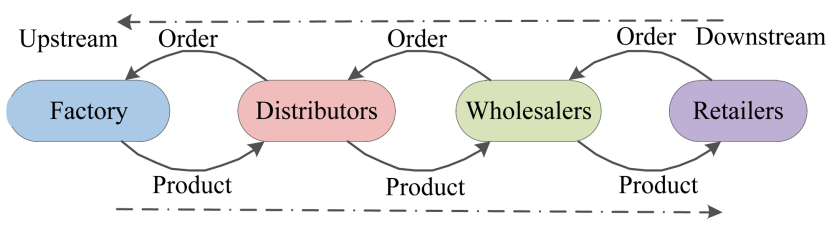

Figure 3. Information flow and material flow.

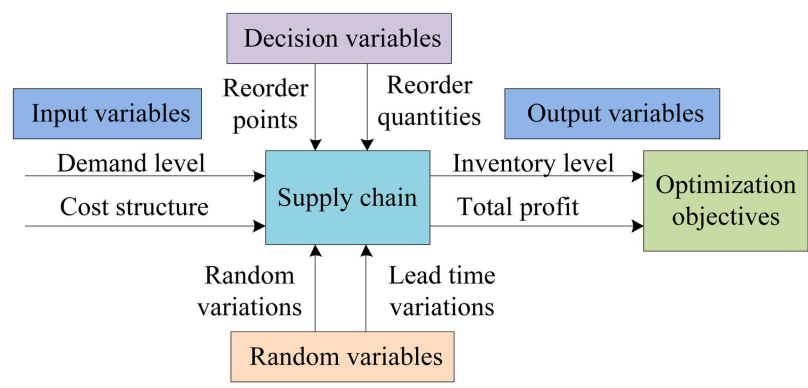

Figure 4. Supply chain simulation system. variables in this model are the reorder points and reorder quantities. In the simulation model, there are two sources of random variations: customer demand and lead time. The Beer Game supply chain is designed to deliver kegs of beer to retail customers. These sales generate revenue when offset by holding cost of inventory and shortage penalty costs, providing a measure of the potential system profitability. Both material and information flows are subject to delays. Customer demand arises at the retail store only. It is assumed that customer demands in different periods (days) are independent, and identically distributed random variables follow a Poisson distribution.

In the proposed model, a fixed quantity ordering system is adopted as the inventory policy, which is also known as $\mathrm{Q}$ model. That is, each enterprise has a fixed reorder point and a fixed reorder quantity. The Beer Game model tracks all inventory levels and their associated costs. The goal of the Beer Game simulation model is to maximize the total net profit and customer service level of the supply chain.

The order processing logic of the retailer is shown in Figure 5. Other companies including distributors, wholesalers, and the factories share a similar order processing logic with retailers. Particularly, when the factories check the inventory level and find out that the inventory level reaches the reorder point, they will not place an order from upstream. Instead, they set up production lines so that they can maintain the inventory level at a reasonable position.

At each level of the supply chain, companies must satisfy orders from their downstream participants (or customers) as much as possible. In the case of a stockout, the excess demand is backlogged. A penalty cost is assessed for backorders at each level of the supply chain reflecting the need to provide good customer service throughout the supply chain. In particular, unfilled demand at the retail level may either be backlogged for

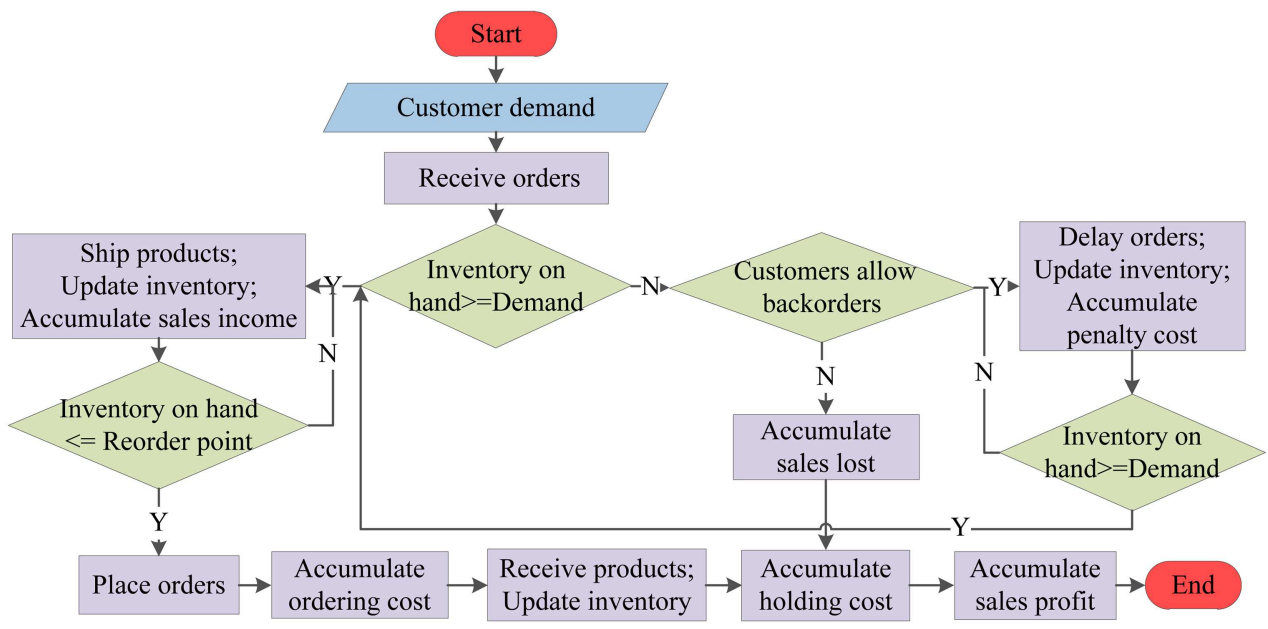

Figure 5. Simulation logic of retailers. 
later delivery or immediately lost. Thus, the unfulfilled retail demand is subject to either penalty cost or lost sale cost.

The Arena Beer Game simulation model tracks inventories and the number of orders at each level of the supply chain. $D$ is the index for day of the month; $L$ is the index for supply chain level, where:

$$
\begin{aligned}
L= & 1 \text { retailer }\}, 2 \text { wholesaler }\}, 3 \text { distributor }\}, \\
& 4\{\text { factory }\} .
\end{aligned}
$$

The model tracks three inventory measures:

- Inventory onhand $(L)$ : It represents the number of units physically in stock;

- Inventory onorder $(L)$ : It represents the number of units that have been ordered, yet have not been received;

- Backorder $(L)$ : It represents the total amount of demand yet to be satisfied.

These inventory measures can be combined to calculate the net inventory position using the following formulation:

Inventory position $(L)=$ Inventory onhand $(L)$

+Inventory onorder $(L)$ - Backorder $(L)$.

The Arena Beer Game simulation model tracks supply chain costs and profits on a daily basis for the four supply chain levels. The cost and profit parameters are shown in Table 2. level by:

The daily operating cost is calculated for each

$$
\begin{aligned}
\text { Cost } & (D, L)=\text { Order cost }(L) \\
& *\{0, \text { if no order placed, otherwise } 1\} \\
& + \text { Holding cost }(\mathrm{L}) * \text { Inventory onhand }(L) \\
& + \text { Penalty cost }(\mathrm{L}) * \text { Backorder }(L) \\
& + \text { Lost sale cost } * \text { Lost sales, if } \\
& L=1, \text { Otherwise } 0\} .
\end{aligned}
$$

The daily profit is calculated for each level by:

$$
\begin{aligned}
\text { Profit }(D, L)= & \text { Unit profit }(L) * \operatorname{Units~sold~}(L) \\
& -\operatorname{Cost}(D, L) .
\end{aligned}
$$

\subsection{Parameters setting and run of the simulation model}

This study aims to investigate the system behavior over the product's production and distribution processes. In the proposed model, a warm-up period of 30 days is set before the simulation model starts to run so as to have a steady running system. The termination time is set as 720 days, namely two years (assuming that each month has 30 days for simplification).

In order to have convergence running results, we have made 30 replications of the system to obtain a good point estimator. The simulation is run by a computer equipped with Intel ${ }^{\circledR}$ Core i5, $3.30 \mathrm{GHz}$ $\mathrm{CPU}$, and $4 \mathrm{~GB}$ RAM. The entire run of this simulation model takes about 7 minutes.

Once we have built a working model, it is time to verify and validate the model. Verification is the task of ensuring that the model behaves as intended; more colloquially, it is known as debugging the model. Validation is the task of ensuring that the model behaves the same as the real system [26].

The verification of the simulation model is to check whether the processing path of orders and products is consistent with the distribution and sale process in the supply chain. Usually, the animation of the simulation model is checked for the verification of the simulation model. The animation of the simulation model (shown in Figure 6) shows that the processing path of orders is consistent with the distribution procedures in the designed supply chain structure.

To validate a simulation mode, the results of our model should be compared with those of the real system. The Beer Game is a representation of a production-distribution system at four levels, which is a simplified version of the supply chain system. The accurate records on the actual system do not exist; then, concentrating on the verification and using the best judgment of experts become an effective and efficient alternative to validate the model [26]. Therefore, the validation analysis for the Beer Game simulation model is to verify the correctness of simulation outputs [29].

Table 2. The setting of cost and profit parameters.

\begin{tabular}{lcccc}
\hline & Retailer & Wholesaler & Distributor & Factory \\
\hline Order cost: $\$$ /order & 25 & 50 & 100 & 200 \\
Holding cost: $\$$ unit day & 0.125 & 0.25 & 0.223 & 0.16 \\
Penalty cost: $\$$ unit day & 5 & 2.5 & 1.25 & 1 \\
Unit profit: $\$$ unit & 4 & 3.75 & 3.5 & 3.25 \\
Lost sale cost: $\$ /$ unit & 10 & - & - & - \\
\hline
\end{tabular}




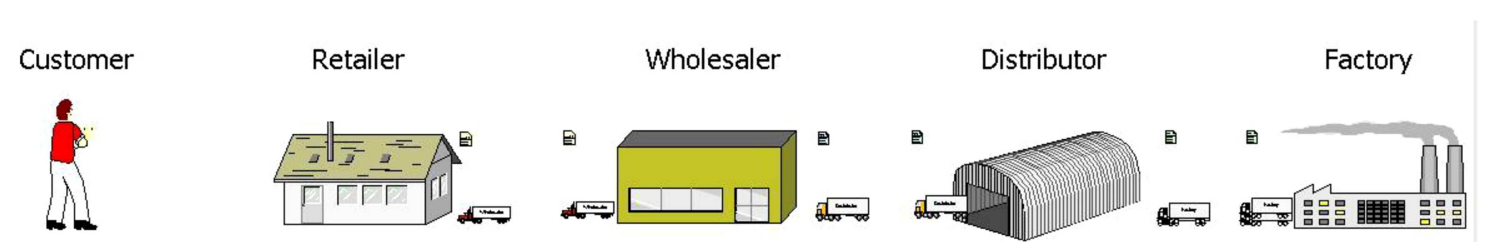

Figure 6. The animation of Beer Game simulation model.

Replications: 30 Time Units: Days

\section{User Specified}

\section{Time Persistent}

\begin{tabular}{lrrrrrr} 
Time Persistent & Average & Half Width & $\begin{array}{r}\text { Minimum } \\
\text { Average }\end{array}$ & $\begin{array}{r}\text { Maximum } \\
\text { Average }\end{array}$ & $\begin{array}{r}\text { Minimum } \\
\text { Value }\end{array}$ & $\begin{array}{r}\text { Maximum } \\
\text { Value }\end{array}$ \\
\hline Kegs Backordered 1 Retailer & 0.00 & .00 & 0.00 & 0.00 & 0.00 & 0.00 \\
Kegs Backordered 2 Wholesaler & 16.4144 & .55 & 13.8889 & 20.2778 & 0.00 & 300.00 \\
Kegs Backordered 3 Distributor & 32.2130 & 1.50 & 25.8333 & 40.7639 & 0.00 & 500.00 \\
Kegs Backordered 4 Factory & 25.9213 & 1.31 & 18.7500 & 37.2222 & 0.00 & 1200.00 \\
Kegs On Hand 1 Retailer & 434.18 & 1.26 & 429.03 & 444.23 & 43.0000 & 838.00 \\
Kegs On Hand 2 Wholesaler & 386.16 & 2.06 & 375.49 & 395.69 & 0.00 & 1000.00 \\
Kegs On Hand 3 Distributor & 339.51 & 3.86 & 319.58 & 356.94 & 0.00 & 1000.00 \\
Kegs On Hand 4 Factory & 360.50 & 3.25 & 335.97 & 377.22 & 0.00 & 900.00 \\
Kegs On Order 1 Retailer & 816.24 & 1.31 & 808.19 & 822.43 & 300.00 & 1300.00 \\
Kegs On Order 2 Wholesaler & 831.04 & 2.10 & 820.49 & 844.72 & 150.00 & 1450.00 \\
Kegs On Order 3 Distributor & 826.32 & 3.09 & 812.08 & 841.53 & 0.00 & 1800.00 \\
Kegs On Order 4 Factory & 266.84 & 3.47 & 254.72 & 297.50 & 0.00 & 2100.00
\end{tabular}

Figure 7. The crystal reports of time persistent statistics.

The Arena Beer Game simulation model provides a wide variety of the simulation results reports available via the Crystal Reports database incorporated into Arena. Figure 7 shows the time-persistent statistics of the Crystal Reports for a complete 24-month simulation run. Arena time-persistent statistics track every change in the reported inventory changes over 30 replicates. The half width means a $95 \%$ confidence-interval half width, which is determined by the sample standard deviation and replication times. The expression of half width is as follows:

$$
\text { Half width }=t_{n-1,1-\alpha / 2} \frac{s}{\sqrt{n}},
$$

where $n$ represents the replication times, $s$ is the sample standard deviation. To some extent, half width is similar to the sample standard deviation. Consider the on-hand stock as an example: The half widths of a retailer, a wholesaler, a distributor, and a factory are $1.26,2.06,3.86$, and 3.25 , respectively. It is obvious that the variation of on-hand stock shows an increasing trend from downstream to upstream of the supply chain, which is a vivid demonstration of bullwhip effect in the multi-echelon supply chain. Thus, we believe that the simulation model is able to capture the key features and relationships in a supply chain system. Therefore, the simulation model is confirmed to be able to represent a real supply chain system.

The simulation model of Beer Game starts from retailers receiving orders from the market. Companies from four echelons of the supply chain are involved in this model. In the simulation system, two sources of uncertainty are considered, that is, customer demand and lead time. To be specific, customer demand can be divided into two parts: fixed demand and fluctuated demand. In terms of the fixed demand, daily demand equals 25. That is, each retailer receives an order of 25 products every day. The fluctuated demand stands for the random fluctuations of the daily demand, which follows a Poisson distribution in this model, as shown in Figure 8.

Another source of uncertainty comes from lead time, which can be divided into two parts: order time and delivery time. Order time refers to the time between the upstream enterprise sending the order and the downstream enterprise receiving the order information. Delivery time refers to the time between the downstream enterprise making delivery and the upstream enterprise receiving the delivered products. To be specific, delivery time can also be divided into 


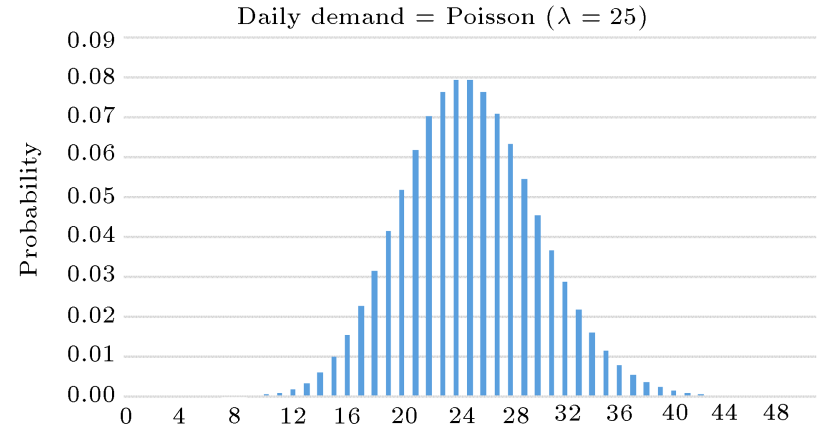

Figure 8. Daily demand.

two parts: fixed delivery time and fluctuated delivery time. The fluctuated delivery time follows a Poisson distribution. Table 3 shows the setting of lead time in this study.

The simulation model tracks the inventory positions and orders of all the companies in the supply chain. The decision parameters of inventory policies are the reorder points and the reorder quantities, which are determined by the following robust parameter design and optimization in Sections 4 and 5 . An example of the retailer inventory analysis is shown in
Table 4, where the initial stock of the retailer is set as 100 units, the reorder point is 100 units, the reorder quantity is 100 units, and the lead time is set as 4 days with no variations.

In this paper, the initial setting of inventory parameters is decided according to the Economic Order Quantity (EOQ) of retailers, wholesalers, distributors, and factory, which can be calculated according to Eq. (2):

$$
\begin{aligned}
& E O Q(L)= \\
& \sqrt{2 * \operatorname{Demand}(L) * \text { Order } \operatorname{cost}(L) / \text { Holding } \operatorname{cost}(L)} .
\end{aligned}
$$

The cost data presented in Table 2 can be used to calculate the $\operatorname{EOQ}(L)$. The EOQ for each level of the supply chain is shown in Table 5. According to the EOQ for each level of the supply chain, the initial values of reorder quantities for each level in the simulation model are determined [15].

The simulation model can be used to analyze the supply chain performance under different settings of decision variables by means of process analyzer, which

Table 3. The setting of lead time.

\begin{tabular}{lcccc}
\hline Lead time & Retailer & Wholesaler & Distributor & Factory \\
\hline Fixed order time & 0 & 2 & 2 & 2 \\
Poisson order time & 0 & 0 & 0 & 0 \\
Fixed ship time & 2 & 2 & 2 & 1 \\
Poisson ship time & 0.5 & 0.5 & 0.5 & 0.5 \\
Total lead time & 4.5 & 4.5 & 4.5 & 1.5 \\
\hline
\end{tabular}

\begin{tabular}{|c|c|c|c|c|c|c|c|c|}
\hline Day & Demand & $\begin{array}{c}\text { Inventory on } \\
\text { hand }\end{array}$ & $\begin{array}{c}\text { Products on } \\
\text { order }\end{array}$ & Backorders & $\begin{array}{c}\text { Inventory } \\
\text { position }\end{array}$ & $\begin{array}{c}\text { Products } \\
\text { ordered }\end{array}$ & $\begin{array}{c}\text { Products } \\
\text { received }\end{array}$ & $\begin{array}{c}\text { Products } \\
\text { sold }\end{array}$ \\
\hline 0 & & 100 & & & 100 & & & \\
\hline 1 & 31 & 69 & & & 69 & 100 & & 31 \\
\hline 2 & 30 & 39 & 100 & & 139 & & & 30 \\
\hline 3 & 25 & 14 & 100 & & 114 & & & 25 \\
\hline 4 & 26 & 0 & 100 & 12 & 88 & 100 & & 14 \\
\hline 5 & 18 & 70 & 100 & & 170 & & 100 & 30 \\
\hline 6 & 23 & 47 & 100 & & 147 & & & 23 \\
\hline 7 & 25 & 22 & 100 & & 122 & & & 25 \\
\hline 8 & 24 & 98 & & & 98 & 100 & 100 & 24 \\
\hline 9 & 22 & 76 & 100 & & & & & 22 \\
\hline 10 & 18 & 58 & 100 & & & & & 18 \\
\hline
\end{tabular}

Table 4. An example of inventory analysis for the retailer.

Table 5. The EOQ for each level of the supply chain.

\begin{tabular}{ccccc}
\hline Order quantities & Retailer & Wholesaler & Distributor & Factory \\
\hline EOQ & 100 & 141 & 299 & 707 \\
Initial values of reorder quantities & 100 & 150 & 300 & 700 \\
\hline
\end{tabular}


is a built-in tool in Arena. The process analyzer is able to show the system performance under many scenarios. In different scenarios, the settings of simulation parameters are different. In addition, the process analyzer helps us evaluate the experiment results in a statistically valid way in the shortest amount of time. As described in Section 3.2, the entire simulation run takes about 7 minutes, while a scenario run in the process analyzer only takes about 11 seconds. Therefore, the process analyzer helps us implement all experiment runs quickly rather than running the simulation model under different combinations of the design parameters separately.

The objective of the supply chain model is to maximize the total profit and customer service level. To be specific, the total profit refers to the sum of net profits of the whole supply chain over a twoyear operation, reflecting the efficiency of supply chain through profitability. The customer service level refers to the product fill rate of retailers over the supply chain, which reflects the effectiveness of the supply chain through customer satisfaction. Therefore, the maximization of profit and customer service level can avoid the potential non-achievement of corporate goals due to the ineffective or inefficient supply chain process.

\section{Robust parameter design using Taguchi method}

Robust Parameter Design (RPD) is a quality improvement technology put forward by Taguchi, which has been widely applied to the optimization design of products and processes. RPD is one of the most efficient quality improvement methods that combines the statistical method with engineering technology. In the simulation model, the input variables are divided into controllable factors and noise factors. The main idea of the RPD is to reduce the variation of the response by selecting the settings combination of the controllable factors. The basic principle of RPD is to make the response insensitive to the changes in the noise factors by taking advantages of the nonlinear relationship between the response and the controllable factors.

\subsection{Controllable factors and noise factors}

Controllable factors can change according to the experiment design. In this paper, controllable factors are the reorder points and reorder quantities, which can be expressed as $\left\{F_{1}, F_{2}, F_{3}, F_{4}, F_{5}, F_{6}, F_{7}, F_{8}\right\}$, shown in Table 6. Noise factors are hard to control or change, and they represent the variations from the market demand and the variations from lead time in this paper. Noise factors are customer demand and lead time of enterprises at each level of the supply chain, which can be expressed as $\left\{D, S_{1}, S_{2}, S_{3}, S_{4}\right\}$. According to the
Table 6. Controllable factors and noise factors.

\begin{tabular}{lcccc}
\hline \multicolumn{1}{c}{ Controllable factors } & \multicolumn{3}{c}{ Settings } \\
\hline Reorder point of retailer, $F_{1}$ & 75 & 100 & 150 \\
Reorder point of wholesaler, $F_{2}$ & 150 & 200 & 300 \\
Reorder point of distributor, $F_{3}$ & 300 & 400 & 600 \\
Reorder point of manufacturer, $F_{4}$ & 150 & 200 & 300 \\
Reorder quantity of retailer, $F_{5}$ & 75 & 100 & 150 \\
Reorder quantity of wholesaler, $F_{6}$ & 150 & 175 & 200 \\
Reorder quantity of distributor, $F_{7}$ & 200 & 300 & 500 \\
Reorder quantity of manufacturer, $F_{8}$ & 600 & 700 & 900 \\
\hline Noise factors & Settings \\
\hline Demand variation, $D$ & 0 & & 1 \\
Ship time variation of retailer, $S_{1}$ & 0.1 & & 0.5 \\
Ship time variation of wholesaler, $S_{2}$ & 0.1 & & 0.5 \\
Ship time variation of distributor, $S_{3}$ & 0.1 & 0.5 \\
Ship time variation of manufacturer, $S_{4}$ & 0.1 & 0.5 \\
\hline
\end{tabular}

perspective of Taguchi, noise factors are the root cause of the variations in products or processes.

\subsection{The cross array design and analysis}

In order to study the effect of different combinations of controllable factor levels, a cross array, including an inner array and an outer array, is used to arrange experiment trials. The inner array is used to arrange the controllable factors in trials through a control array of factorial design, while the outer array is used to study the difference between the same trial of the inner array and different settings of noise factors. The products of the inner array and the outer array become the cross array. According to the number of controllable factors and noise factors and their corresponding levels in this study, the inner array is set as orthogonal $L_{27}\left(3^{8}\right)$, while the outer array is set as orthogonal $L_{8}\left(2^{5}\right)$.

This paper adopts the location and dispersion modeling method to analyze the experiment's results. To be specific, the mean of response samples from the repeated experiments with noise factors is used as the measure of location, while the standard deviation of the response samples is used as the measure of dispersion. Factors that significantly influence the measure of location are defined as the location factors, while factors that significantly influence the measure of dispersion are defined as the dispersion factors.

When the location and dispersion modeling method is used, different strategies are adopted according to different types of optimization problems. Taguchi mentioned three kinds of quality characteristics: "the larger the better", "the nominal the best", and "the smaller the better", while this paper only refers to two of them.

For "the larger the better" problem, the levels of location factors are first decided to maximize the 
total location; then, the levels of dispersion factors are decided to minimize the total dispersion.

For "the smaller the better" problem, the levels of location factors are first decided to minimize the total location; then, the levels of dispersion factors are decided to minimize the total dispersion.

It is worth noting that the first step in the location and dispersion modeling method is to maximize the signal-to-noise ratio (SNR) of responses. Signal-tonoise ratio is used to evaluate the superiority of the controllable factors combinations and the robustness of the corresponding responses. In this paper, the robust parameter design meant to maximize the profit and customer service level is conducted separately for each objective. Thus, the related two kinds of signal-tonoise ratio are introduced under the maximization and minimization optimization goals, respectively.

Assume that the measured values of the response are $y_{1}, y_{2}, y_{3} \ldots y_{m}$, respectively, where the estimate of mean is $\bar{y}$ and the estimate of variation is $s^{2}$ based on two different optimization goals: maximization and minimization. The corresponding SNR is defined as in Eqs. (3) and (4):

The smaller the better: $S N_{S}=-10 \log \left(\frac{1}{m} \sum_{i=1}^{m} \bar{y}^{2}\right)_{(3)}$

The larger the better: $S N_{L}=-10 \log \left(\frac{1}{m} \sum_{i=1}^{m} \frac{1}{\bar{y}^{2}}\right)$.

Here, an experiment used for the total profit maximization of the supply chain is introduced.

According to the main effect plots of Figures 9-11, it is easy to determine how each factor influences the response in location and dispersion perspectives. To be specific, the ranks of the main effects of SNR and mean values for total profit are similar, meaning that the maximization of means is consistent with that of SNRs. According to the ranks of each factor's main effect on the mean and dispersion of the response, the classification of factors can be obtained, as shown in Figure 12.

The total profit of the supply chain can be optimized according to the location and dispersion modeling method. To be specific, first, the optimal combination of the location factors that maximizes the mean values of the response. Then, the optimal combination of the dispersion factors minimizes the standard deviation values of the response. Meanwhile, the above optimization steps should follow the principle of the SNRs maximization. Thus, the optimal combination of controllable factors can be obtained as follows:

$$
\begin{aligned}
& \left\{F_{1}, F_{2}, F_{3}, F_{4}, F_{5}, F_{6}, F_{7}, F_{8}\right\} \\
& \quad=\{100,150,400,150,100,150,300,700\} .
\end{aligned}
$$

The predicted total profit is $y_{P}=1685713.0765$ and $S N R_{P}=124.596$. The confirmation experiment shows that $y_{P}^{*}=1572497.7545$ and $S N R_{P}^{*}=123.9266$.

The confirmation experiments are conducted under eight sets of noise factors combinations (see outer array $\left.L_{8}\left(2^{5}\right)\right)$. Therefore, a general result can be obtained. Based on the comparison of the confirmation results and the predicted result, it is observed that the robust parameter design of profit maximization has achieved the optimization goal well, verifying the effectiveness of the Taguchi method.

The parameter design of customer satisfaction maximization can be conducted following similar steps.

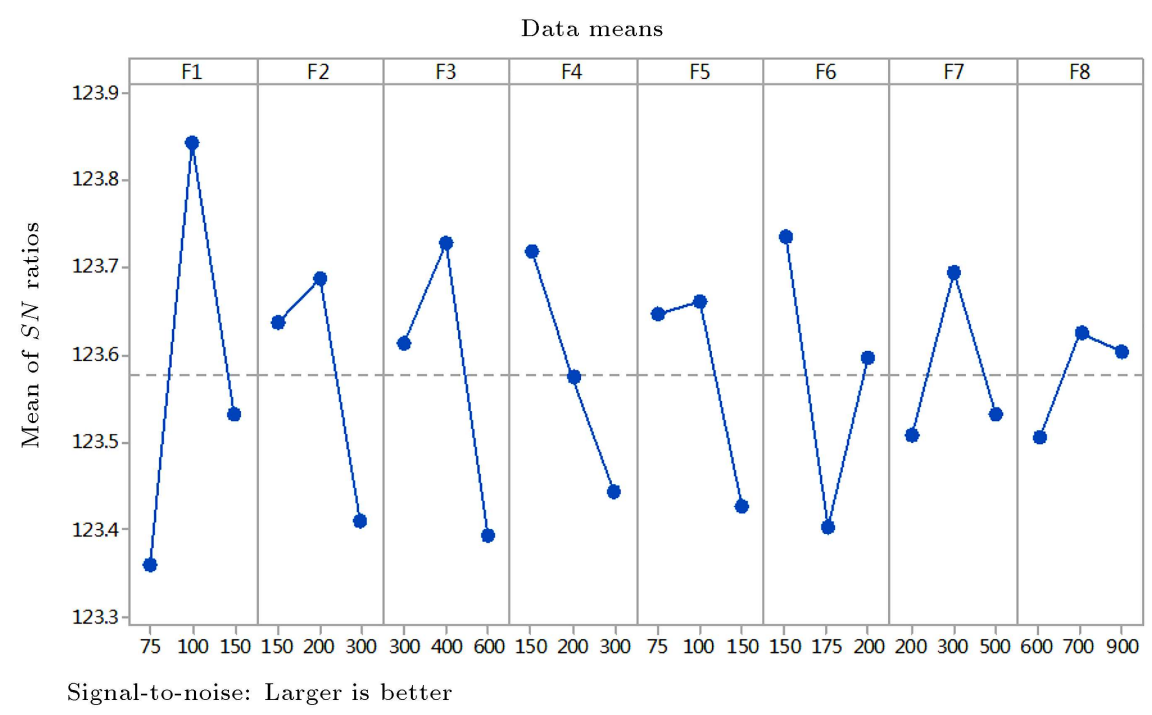

Figure 9. Main effects plot for SNRs. 


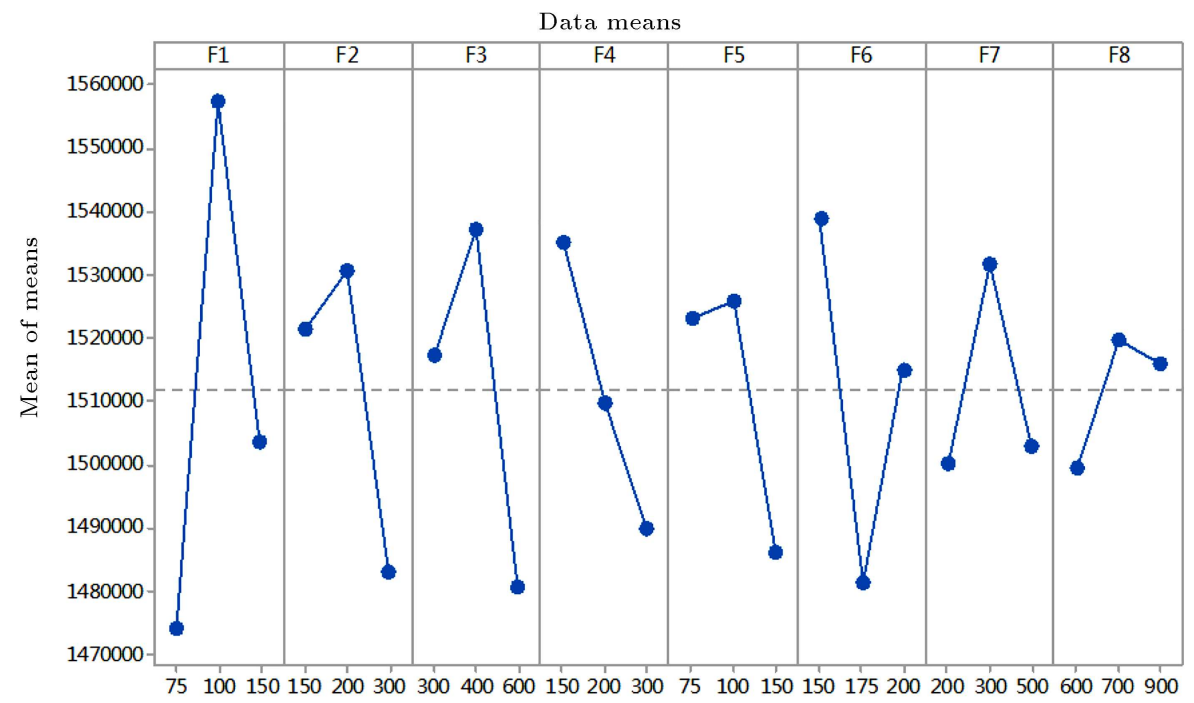

Figure 10. Main effects plot for means.

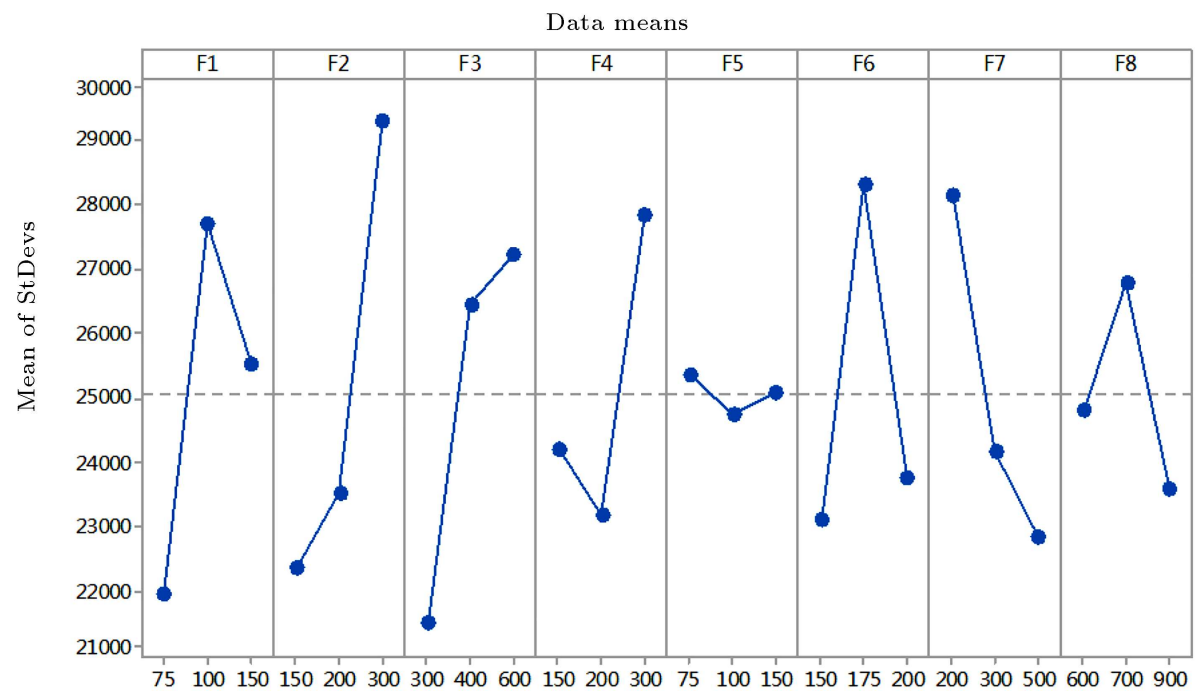

Figure 11. Main effects plot for SDs.

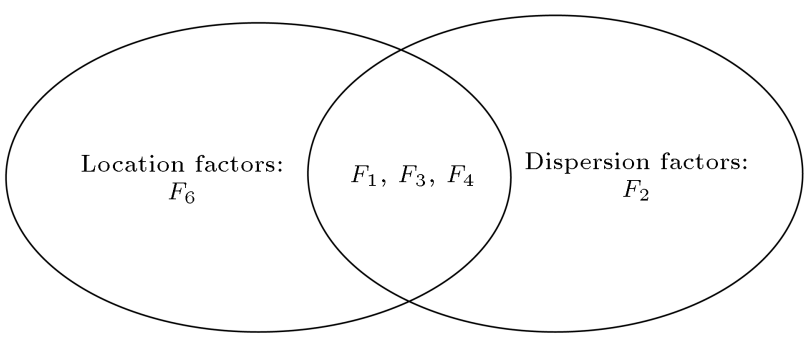

Figure 12. Location factors and dispersion factors.

The optimal parameter setting for the customer service maximization is:

$$
\begin{aligned}
& \left\{F_{1}, F_{2}, F_{3}, F_{4}, F_{5}, F_{6}, F_{7}, F_{8}\right\} \\
& \quad=\{150,300,300,200,150,200,500,700\} .
\end{aligned}
$$

The predicted customer service level is $y_{C}=$ 1.02563 and $S N R_{C}=0.295542$. Since the range of customer service level is $y_{C} \in(0,1]$, the predicted value should be altered to $y_{C}=1$. The confirmation experiment shows that $y_{C}^{*}=0.9975$ and $S N R_{I}^{*}=$ -0.02163 . Thus, the confirmation result also verifies the effectiveness of the Taguchi method.

\section{Optimization analysis using RSM}

Response Surface Methodology (RSM) was first put forward by Box and Wilson [21] and, then, became a popular parameter optimization method that combines mathematics with statistical analysis. In order to optimize the proposed supply chain model, we have to study how the response variable depends on the independent variables. RSM aims to obtain the optimal response value (maximization, minimization or to the target) by selecting a combination of the controllable factors. To be specific, RSM follows a sequential 
process for designing experiments and fitting models from the experiment data [30].

The first step of RSM is to identify the significant factors that influence the output response, known as the variable selection. Then, the first-order regression model is adopted to fit the relationship between factors and responses. After that, a full factorial design is conducted to check the presence of the curvature. If there is a curvature in the experiment region (optimum experiment region), the second-order or higher-order regression model is adopted to fit the experiment data. Otherwise, the steepest descent/ascent method is adopted to further explore the optimum experiment region. Furthermore, the multi-response optimization can be applied to study bi-objective or multi-objective problems.

\subsection{Variable selection and optimum search}

The main idea of response surface methodology is to estimate the function relations between the response variables and independent variables based the experiment data, where a simple linear regression model is often adopted to fit the linear relations, as shown in Eq. (5):

$$
E(Y)=\beta_{0}+\beta_{1} X_{1}+\beta_{2} X_{2}+\ldots+\beta_{n} X_{n} .
$$

When there is a significant curvature, a higher order polynomial is adopted to fit the model. The implementation of RSM follows three steps:

1. Using a low-order polynomial to estimate the function relations between the response variables and the independent variables at certain intervals;

2. Using the steepest descent (ascent) method to determine the maximum descent (ascent) direction of the response values and move the independent variables along the specific direction step by step to search for the optimum area, which shows a significant curvature;

3. Using a higher order polynomial to further estimate the function relations between the response variables and the independent variables at certain intervals in order to obtain a better fitting model.

In order to reduce the arbitrariness in selecting the starting experiment region, this paper uses the optimal combinations of controllable factors obtained by Taguchi method as the initial points to conduct RSM design. For simplification, the independent variables are universally coded at the interval $(-1,1)$, and the code method is shown in Eq. (6):

$$
X_{i}=\frac{\text { Natural facor level }\left(\mathrm{x}_{\mathrm{i}}\right)-\text { Initial facor level }}{\text { Half interval width }}
$$

Here, consider the experiment design of profit maximization as an example. First, a $2^{(8-2)}$ fractional factorial experiment is conducted to select significant factors that influence the total profit. The Pareto chart

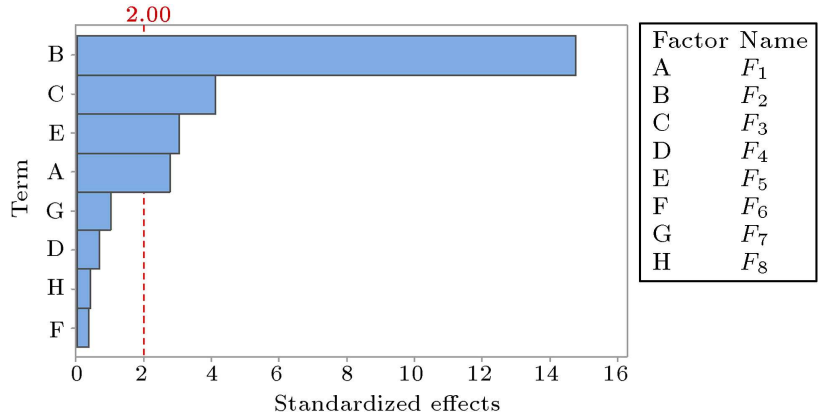

Figure 13. The Pareto chart of the fractional factorial experiment of profit (response is profit, $\alpha=0.05$ ).

of this experiment results shows that $\left\{F_{2}, F_{3}, F_{5}, F_{1}\right\}$ are significant factors in the response, as shown in Figure 13.

Then, the next step is to design a $\left(2^{4}+4\right)$ full factorial experiment with center points for the significant factors to estimate the function relationship between the response and independent variables. The first-order fitting model is presented in Eq. (7).

$$
\begin{aligned}
Y= & 1416435-20964 X_{1}+76890 X_{2}+24768 X_{3} \\
& -30218 X_{5} .
\end{aligned}
$$

The ANOVA of $\left(2^{4}+3\right)$ experiment shows significant evidence of curvature. Therefore, the optimum area is found. The following Central Composite Face-centered (CCF) discussed in Section 5.2 is conducted to further fit this experiment model.

Similarly, the analysis of the $2^{(8-2)}$ fractional factorial design of CSL shows that $\left\{F_{1}, F_{5}, F_{2}, F_{8}, F_{3}\right\}$ are the significant factors in the response, as shown in Figure 14.

Then, the $2^{5}$ full factorial experiment of CSL shows the first-order fitting model for the customer service level maximization as in Eq. (8):

$$
\begin{aligned}
Y= & 0.943431+0.053625 X_{1}+0.005038 X_{2} \\
& +0.003381 X_{3}+0.010881 X_{5}+0.000288 X_{8} .
\end{aligned}
$$

The ANOVA of the full factorial experiment with center points $\left(2^{5}+3\right)$ for CSL maximization shows significant evidence of curvature. Then, axial points are added to the full factorial experiment with center points $\left(2^{5}+3\right)$ in order to analyze the non-linear relations between the CSL and inventory parameters, as addressed in Section 5.2.

\subsection{The analysis of the second-order response surface design}

The general form of a second-order fitting model in the response surface design is presented in Eq. (9): 


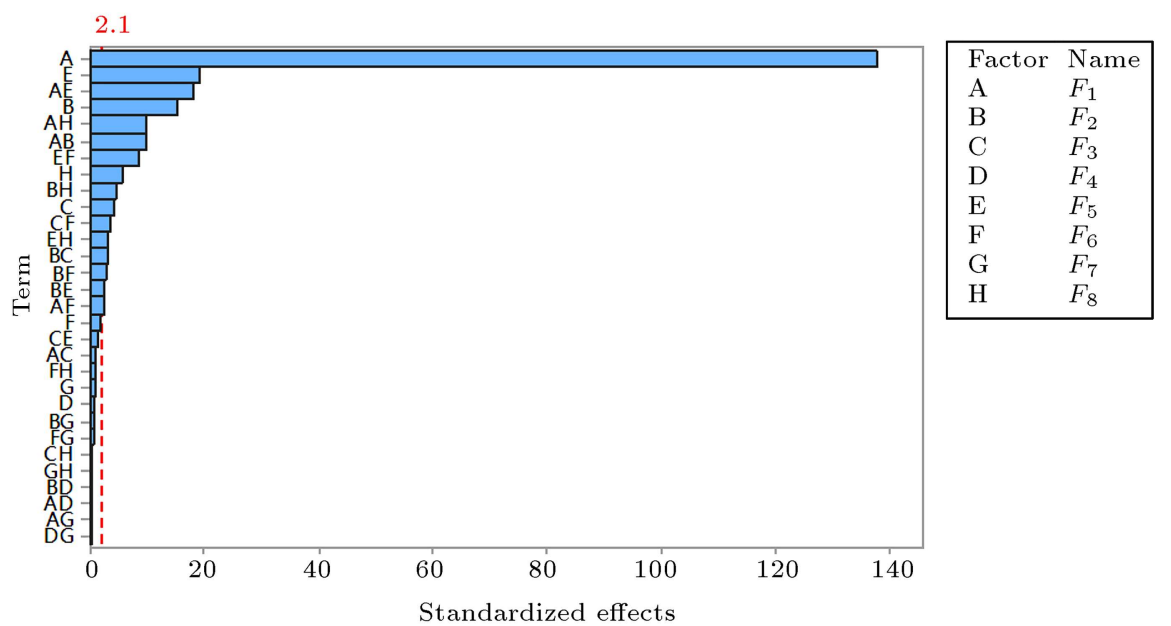

Figure 14. The Pareto chart of the fractional factorial experiment of CSL (response is CSL, $\alpha=0.05$, only 30 effects shown).

$$
\begin{aligned}
& E(Y)=\beta_{0}+\sum_{i=1}^{k} \beta_{1} X_{i}+\sum_{i=1}^{k} \beta_{i i} X_{i}^{2} \\
& +\sum_{i=1}^{k} \sum_{j}^{k} \beta_{i j} X_{i} X_{j} .
\end{aligned}
$$

In Eq. (9), $k$ stands for the number of independent variables. When there is a significant curvature in the first-order linear model, a second-order model should be adopted in order to improve the fitting effect of the model.

According to the sequential principle of the RSM, the second-order fitting model can be obtained by adding axial points into the former full factorial experiment. By adding $2 k$ face-center points, where $k$ stands for the number of factors, the full factorial experiment can be transformed into central Composite Face-centered (CCF) design. The reason for choosing face-center points, instead of axial points, comes from the boundary limits of factors' values.

According to the CCF experiment for profit maximization, the ANOVA result shows that the derived second-order response model is significant, as shown in Eq. (10):

$$
\begin{aligned}
Y_{P}= & 1527832-19228 X_{1}+74316 X_{2}+25217 X_{3} \\
& -31763 X_{5}-56744 X_{2}^{2}-38160 X_{3}^{2}+20973 X_{1} X_{2} \\
& +26275 X_{1} X_{3}+13550 X_{3} X_{5} .
\end{aligned}
$$

Therefore, this second-order model can be adopted to predict the optimal response. The optimal combination of factors is $\left\{F_{1}^{*}, F_{2}^{*}, F_{3}^{*}, F_{5}^{*}\right\}=$ $\{120,175,462,75\}$, as shown in Figure 15 . The predicted total profit is $y_{p}=1577220$, with the desirability $d=0.92374$. The confirmation experiment shows that $y_{P}^{*}=1581511.1917$.

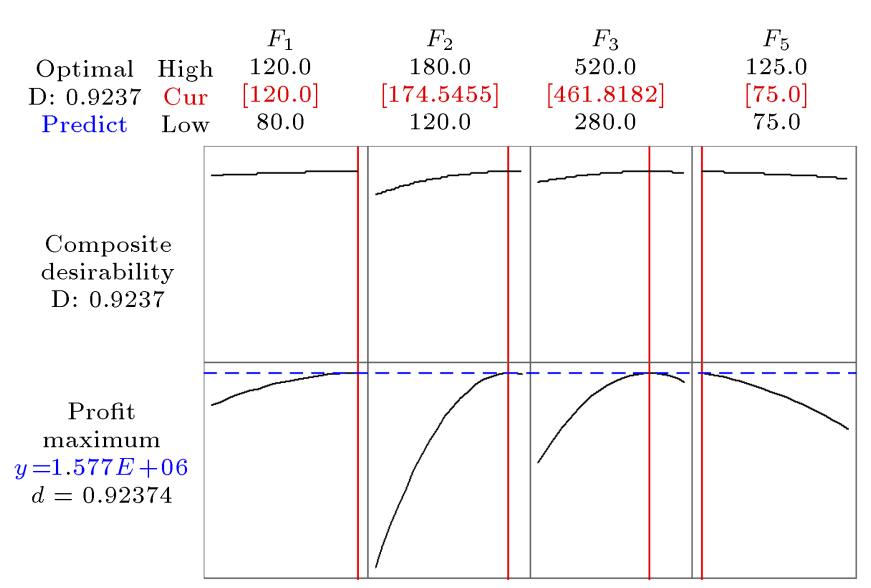

Figure 15. The optimization plot of profit maximization.

Similarly, the second-order response model of CSL can be obtained, by Eq. (11):

$$
\begin{aligned}
Y_{C}= & 0.99065+0.053626 X_{1}+0.004288 X_{2} \\
& +0.002265 X_{3}+0.010126 X_{5}-0.04559 X_{1}^{2} \\
& -0.02803 X_{1} X_{2}+0.009366 X_{1} X_{5} \\
& -0.004228 X_{2} X_{5} .
\end{aligned}
$$

The optimal combination of factors in the CSL maximization can be obtained as follows:

$$
\left\{F_{1}^{*}, F_{2}^{*}, F_{3}^{*}, F_{5}^{*}, F_{8}^{*}\right\}=\{175,210,500,200,600\}
$$

The predicted customer service level is $y_{C}=$ 1.0149, with the desirability $D=1$. For $y_{C} \in(0,1]$, the predicted value should be altered to be $Y_{c}=1$. The confirmation experiment shows that $y_{C}^{*}=0.9987$. 


\subsection{Multi-response optimization}

The above sections discussed the response surface design with a single response problem. In many practical situations, however, problems involving multiple responses need to be considered.

In the response surface design for profit maximization, $\left\{F_{1}, F_{2}, F_{3}, F_{5}\right\}$ are the significant factors, and $\left\{F_{1}, F_{2}, F_{3}, F_{5}, F_{8}\right\}$ are the significant factors in customer service level maximization. Therefore, four factors of $\left\{F_{1}, F_{2}, F_{3}, F_{5}\right\}$ need to be considered in the multi-response RSM design for the bi-objective problems of profit and CSL maximization.

According to the optimal solutions of single response optimization, the settings of significant factors for the multi-response optimization can be obtained, as shown in Table 7 .

A four-factor CCF design of the experiment is conducted, and the ANOVA result shows that the second-order response models for profit and CSL maximization are significant, as shown in Eqs. (12) and (13):

$$
\begin{aligned}
Y_{P}= & 1557965-64886 X_{1}+132071 X_{2}+62543 X_{3} \\
& -37299 X_{5}-154284 X_{2}^{2}-62272 X_{3}^{2} \\
& +57082 X_{1} X_{2}+40735 X_{1} X_{3}-25581 X_{1} X_{5} \\
& +75888 X_{2} X_{5}+22412 X_{3} X_{5} \\
Y_{C}= & 0.99008+0.07897 X_{1}+0.02686 X_{2}+0.00382 X_{3} \\
& -0.06486 X_{1}^{2}-0.01751 X_{2}^{2}-0.01509 X_{1} X_{2} \\
& -0.00382 X_{2} X_{3}+0.00824 X_{2} X_{5}
\end{aligned}
$$

When multiple responses are considered simultaneously in the RSM design, the weight for each response should be clarified. In response optimizer, the weight has a value range of $[0.1,10]$. Here, two decision scenarios of multi-response optimization are discussed.

- Scenario 1: Decision-makers pay much attention to the total profit of the supply chain, while they are less concerned with the customer service level. Under this circumstance, the weight ratio of profit and CSL is 10:0.1.

Table 7. The setting of factors for multi-response optimization.

\begin{tabular}{lcccc}
\hline Factors & $\boldsymbol{F}_{\mathbf{1}}$ & $\boldsymbol{F}_{\mathbf{2}}$ & $\boldsymbol{F}_{\mathbf{3}}$ & $\boldsymbol{F}_{\mathbf{5}}$ \\
\hline Low level & 100 & 120 & 300 & 70 \\
High level & 200 & 400 & 550 & 150 \\
\hline
\end{tabular}

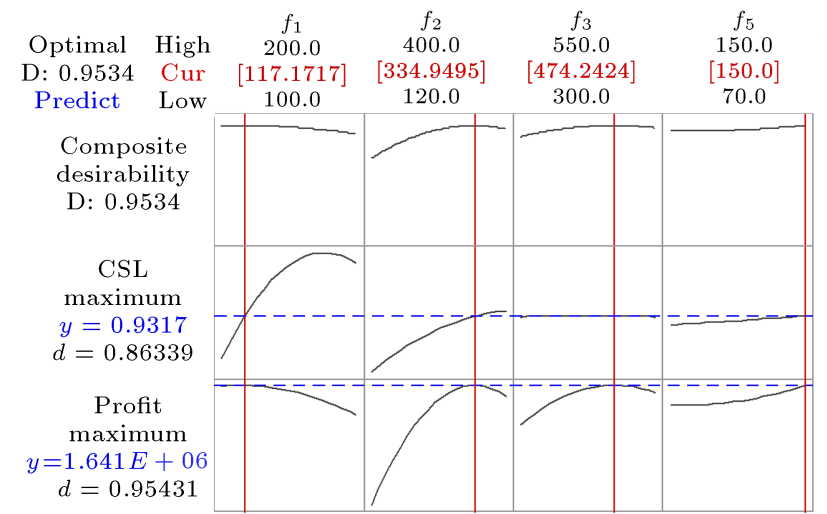

Figure 16. The optimization plot for profit and CSL with a weight ratio of 10:0.1.

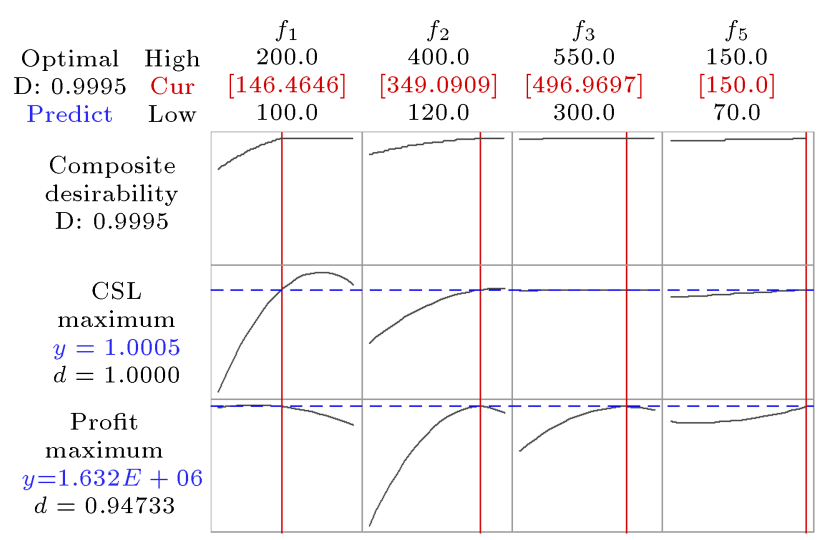

Figure 17. The optimization plot for profit and CSL with a weight ratio of $0.1: 10$.

The optimization plot under this circumstance is shown in Figure 16. Based on Figure 16 , the optimal solution is $\left\{F_{1}^{*}, F_{2}^{*}, F_{3}^{*}, F_{5}^{*}\right\}=$ $\{117,335,474,150\}$. The predicted total profit is 1641000 , and the predicted CSL is $93.17 \%$. To be specific, the reorder point of the retailer is 117 , the reorder point of the wholesaler is 335 , the reorder point of the distributor is 474 , and the reorder quantity of the retailer is 150 . The confirmation experiment shows that the total profit is 1597787 , and the customer service level is $94.31 \%$.

- Scenario 2: Decision-makers are much more focused on the customer service level. The total profit is not a major concern. Under this circumstance, the weight ratio of profit and CSL is 0.1:10.

The optimization plot under this circumstance is presented in Figure 17. The optimal solution here is $\left\{F_{1}^{*}, F_{2}^{*}, F_{3}^{*}, F_{5}^{*}\right\}=\{146,349,497,150\}$. The predicted total profit is 1632000 , and the predicted CSL is $100.05 \%$. For $C S L \in(0,1]$, the predicted value should be altered to $100 \%$. The confirmation experiment shows that the optimal total profit is 1588268 , and the optimal customer service level is $98.88 \%$. 
Table 8. The comparison of optimal solutions by different methods.

\begin{tabular}{clcccccccccc}
\hline Objective & Method & $\boldsymbol{F}_{\mathbf{1}}$ & $\boldsymbol{F}_{\mathbf{2}}$ & $\boldsymbol{F}_{\mathbf{3}}$ & $\boldsymbol{F}_{\mathbf{4}}$ & $\boldsymbol{F}_{\mathbf{5}}$ & $\boldsymbol{F}_{\mathbf{6}}$ & $\boldsymbol{F}_{\mathbf{7}}$ & $\boldsymbol{F}_{\mathbf{8}}$ & Optimum & Improvement \\
\hline \multirow{2}{*}{$\begin{array}{c}\text { Maximize } \\
\text { profit }\end{array}$} & Kumar et al. [15] & 100 & 200 & 400 & 200 & 100 & 150 & 300 & 700 & 1561619 & - \\
& This paper & $120^{*}$ & $175^{*}$ & $462^{*}$ & 150 & $75^{*}$ & 150 & 300 & 700 & 1581511 & $1.27 \%$ \\
& & & & & & & & & & \\
\multirow{2}{*}{$\begin{array}{c}\text { Maximize [13,14,16,23,25] } \\
\text { CSL }\end{array}$} & Kumar et al. [15] & 100 & 150 & 400 & 150 & 100 & 150 & 300 & 700 & 1572498 & $0.70 \%$ \\
& Thuchi [13,14,16,23,25] & 150 & 300 & 300 & 200 & 150 & 200 & 500 & 700 & $99.75 \%$ & $12.31 \%$ \\
\hline
\end{tabular}

*Factors with star sign represent the significant factors involved in the modeling process.

Based on the above scenarios, it is clear that different weight settings between responses have a great impact on the final optimal solution. Therefore, it is crucial to figure out the weight of each objective in this multi-response optimization problem, which usually depends on the characteristics of a supply chain and the opinions from supply chain managers.

\section{Discussions and conclusions}

In the supply chain inventory management, demand uncertainty and variations from lead time have significant impacts on the performance of the whole supply chain. Furthermore, these uncertainty problems may constitute a severe threat to the balance and stability of the supply chain system. Therefore, it is of great importance to improve the robustness of the supply chain by reducing the sensitivity of the supply chain system from variations.

In this paper, Robust Parameter Design (RPD) was proposed to solve inventory policy optimization problems. Based on the supply chain simulation model, Taguchi method and response surface methodology were sequentially adopted to conduct robust parameter design. Taguchi method was used to locate the optimum experiment area quickly, which can effectively reduce the influence of noise factors' fluctuations. Response surface methodology was able to derive the optimal response at continuous intervals of variables. Furthermore, the multi-response optimization design for profit maximization and inventory minimization was discussed under two decision scenarios, which can give some insights into the practitioners in the supply chain management.

The effectiveness of the proposed methodology can be shown through a comparison of optimal solutions from different methods. The setting of inventory parameters, including reorder points and reorder quantities, is the key decision problem in this paper. In the simulation model, the initial values of reorder quantities at each level were determined according to the EOQ for each level, shown in Table 5. In addition, the setting of inventory parameter in the simulation model refers to the embedded optimization results from Kumar et al. [15]. The robust parameter design is widely used in the optimization of supply chain simulation models, as shown in Table 1 . The proposed sequential robust parameter design in this paper was compared with Taguchi method [13,14,16,23,25] and embedded optimization method from Kumar et al. [15]. The comparison results are presented in Table 8 .

According to Table 8, for profit maximization, the optimal setting of reorder quantities from Taguchi method $[13,14,16,23,25]$ is consistent with the optimization results of Kumar et al. [15], which are determined from the EOQ values [15]. This is because of the common goal shared with both the EOQ model and Taguchi method, namely profit maximization. Therefore, the effectiveness of the Taguchi method can be verified. In the proposed sequential RPD approach, the Taguchi method was adopted to determine the optimal combination of inventory parameters at their discrete level; then, based on the discrete optimization solution from Taguchi method, RSM was able to solve the optimal setting of inventory parameters at their continuous level. Therefore, the improvement of the proposed approach was more significant than the Taguchi method.

In general, the proposed approach in this paper showed its effectiveness through the comparison of different methods. To be specific, the improvement of the proposed methodology for customer service level maximization was proved to be more significant than that for profit maximization with a $12.44 \%$ improvement. In addition, the proposed RPD method was more efficient in the experiment design than other embedded optimization algorithms through its statistical way of selecting experiment points, which often result in considerable saving of experiment time.

In supply chain management, bullwhip effect is a 
popular problem. How to quantify and control bullwhip effect from the perspective of robust parameter design may become an interesting topic for further study.

\section{Acknowledgements}

This work is supported by the National Natural Science Foundation of China (Nos. 71771121, 71371099, and 71471088), the China Postdoctoral Science Foundation (Nos. 2014T70527 and 2013M531366), the Natural Science Foundation for Jiangsu Province (No. BK20170810), and the Fundamental Research Fund for the Central Universities (No. 3091511102).

\section{References}

1. Merkuryev, Y., Merkuryeva, G., Piera, M., and Guasch, A., Supply Chain Dynamics, Springer, London (2009).

2. Vieira, G.E. "Ideas for modeling and simulation of supply chains with Arena", Proceedings of the 2004 Winter Simulation Conference, 2, pp. 1418-1427 (2004).

3. Vieira, G.E. and Júnior, O.C. "A conceptual model for the creation of supply chain simulation models", Proceedings of the 2005 Winter Simulation Conference, pp. 2619-2627 (2005).

4. Tabrizi, M.M., Karimi, B., and Mirhassani, S. "A novel two-stage stochastic model for supply chain network design under uncertainty", Scientia Iranica, Transactions E, Industrial Engineering, 23(6), p. 3046 (2016).

5. Mahmoodi, A., Haji, A., and Haji, R. "A twoechelon inventory model with perishable items and lost sales", Scientia Iranica, Transactions E, Industrial Engineering, 23(5), p. 2277 (2016).

6. Badri, H., Fatemi Ghomi, S.M.T., and Hejazi, T.-H. "A two-stage stochastic programming model for valuebased supply chain network design", Scientia Iranica, Transactions E, Industrial Engineering, 23(1), p. 348 (2016).

7. Rooeinfar, R., Azimi, P., and Pourvaziri, H. "Multiechelon supply chain network modelling and optimization via simulation and metaheuristic algorithms", Scientia Iranica, Transactions E, Industrial Engineering, 23(1), p. 330 (2016).

8. Tsai, S.C. and Chen, S.T. "A simulation-based multiobjective optimization framework: A case study on inventory management", Omega, 70, pp. 148-159 (2017).

9. Ye, W. and You, F. "A computationally efficient simulation-based optimization method with regionwise surrogate modeling for stochastic inventory management of supply chains with general network structures", Computers \& Chemical Engineering, 87, pp. 164-179 (2016).
10. Keyvanshokooh, E., Ryan, S.M., and Kabir, E. "Hybrid robust and stochastic optimization for closed-loop supply chain network design using accelerated Benders decomposition", European Journal of Operational Research, 249(1), pp. 76-92 (2016).

11. Chu, Y., You, F., Wassick, J.M., and Agarwal, A. "Simulation-based optimization framework for multiechelon inventory systems under uncertainty", Computers \& Chemical Engineering, 73, pp. 1-16 (2015).

12. Shi, W., Liu, Z., Shang, J., and Cui, Y. "Multicriteria robust design of a JIT-based cross-docking distribution center for an auto parts supply chain", European Journal of Operational Research, 229(3), pp. 695-706 (2013).

13. Hussain, M., Drake, P.R., and Lee, D.M. "Quantifying the impact of a supply chain's design parameters on the bullwhip effect", International Journal of Physicial Distribution \& Logistics Management, 42(10), pp. 947968 (2012).

14. Yang, T., Wen, Y.-F., and Wang, F.-F. "Evaluation of robustness of supply chain information-sharing strategies using a hybrid Taguchi and multiple criteria decision-making method", International Journal of Production Economics, 134(2), pp. 458-466 (2011).

15. Kumar, S., Chandra, C., and Seppanen, M.S. "Demonstrating supply chain parameter optimization through beer game simulation", InformationKnowledge-Systems Management, 6(4), pp. 291-322 (2007).

16. Shang, J.S., Li, S., and Tadikamalla, P. "Operational design of a supply chain system using the Taguchi method, response surface methodology, simulation, and optimization", International Journal of Production Research , 42(18), pp. 3823-3849 (2004).

17. Shi, W., Shang, J., Liu, Z., and Zuo, X. "Optimal design of the auto parts supply chain for JIT operations: Sequential bifurcation factor screening and multi-response surface methodology", European Journal of Operational Research, 236(2), pp. 664-676 (2014).

18. Nair, V.N., Abraham, B., MacKay, J., et al. "Taguchi's parameter design: a panel discussion", Technometrics, 34(2), pp. 127-161 (1992).

19. Robinson, T.J., Borror, C.M., and Myers, R.H. "Robust parameter design: a review", Quality and Reliability Engineering International, 20(1), pp. 81-101 (2004).

20. Montgomery, D.C., Design and Analysis of Experiments, John Wiley \& Sons (2008).

21. Box, G.E.P. and Wilson, K.B. "On the experimental attainment of optimum conditions", Journal of the Royal Statistical Society: Series B, 13(1), pp. 1-38 (1951). 
22. Myers, R.H. and Montgomery, D.C., Response Surface Methodology: Process and Product Optimization Using Designed Experiments, Wiley Series in Probability and Statistics, New York (1995).

23. Dellino, G., Kleijnen, J.P., and Meloni, C. "Robust optimization in simulation: Taguchi and response surface methodology", International Journal of Production Economics, 125(1), pp. 52-59 (2010).

24. Tong, L.I., Su, C.T., and Wang, C.H. "The optimization of multi-response problems in the Taguchi method", International Journal of Quality \& Reliability Management, 14(4), pp. 367-380 (1997).

25. Shukla, S.K., Tiwari, M., Wan, H.-D., and Shankar, R. "Optimization of the supply chain network: Simulation, Taguchi, and psychoclonal algorithm embedded approach", Computers \& Industrial Engineering, 58(1), pp. 29-39 (2010).

26. Tiwari, M.K., Raghavendra, N., Agrawal, S., and Goyal, S. "A hybrid Taguchi-Immune approach to optimize an integrated supply chain design problem with multiple shipping", European Journal of Operational Research, 203(1), pp. 95-106 (2010).

27. Li, Y.C. and Liao, H.C. "The optimal parameter design for a blood supply chain system by the Taguchi method", International Journal of Innovative Computing, Information and Control, 8(11), pp. 7697-7712 (2012).

28. Kelton, D. and Sturrock, D., Simulation with Arena, 6th Ed., McGraw-Hill, New York (2015).

29. Soleimani, H. and Kannan, G. "A hybrid particle swarm optimization and genetic algorithm for closedloop supply chain network design in large-scale networks", Applied Mathematical Modelling, 39(14), pp. 3990-4012 (2015).

30. Osorio, A.F., Brailsford, S.C., Smith, H.K., Forero-Matiz, S.P., and Camacho-Rodriguez, B.A. "Simulation-optimization model for production planning in the blood supply chain", Health Care Management Science, 20(4), pp. 548-564 (2017).

31. Liu, Y.S., Tang, L.N., Ma, Y.Z., and Yang, T. "TFT-LCD module cell layout design using simulation and fuzzy multiple attribute group decision-making approach", Applied Soft Computing, 68, pp. 873-888 (2018).

\section{Biographies}

Li-Na Tang is currently a PhD Student at the Department of Management Science and Engineering at Nanjing University of Science and Technology of China. She received the BS in Business Management from Nanjing University of Science and Technology of China. Her research interests include computer simulation, process modeling, and design of experiments.
Yi-Zhong $\mathbf{M a}$ is a Professor at the Department of Management Science and Engineering at Nanjing University of Science and Technology. He received his BSc in Applied Mathematics from Huazhong Normal University, Wuhan, China and his MSc in Quality Engineering and $\mathrm{PhD}$ in Control Science from Northwestern Polytechnical University, China. $\mathrm{He}$ is an executive director of several associations such as Quality Society of China (QSC), Society of Management Science and Engineering of China (SMSEC), and Chinese Society of Optimization, Overall Planning and Economical Mathematics. His research interests include quality engineering and quality management.

Jian-Jun Wang is an Associate Professor at the Department of Management Science and Engineering at Nanjing University of Science and Technology. He received his BSc in Applied Mathematics from Jishou University, China and his MSc in Applied Statistics from Hunan University. He earned his PhD in Quality Engineering from Nanjing University of Science and Technology, China. He is a member of QSR and INFORMS and a senior member of Chinese Society of Optimization, Overall Planning and Economical Mathematics. He has authored over 50 refereed journal publications and is a reviewer of several international journals such as EJOR, IJPR, CIE, and QTQM. His research interests include parameter design and optimization, Bayesian statistics and modeling, industrial statistical and data analysis.

Lin-Han Ouyang received his $\mathrm{PhD}$ in Management Science and Engineering from Nanjing University of Science and Technology and his BS in Industrial Engineering form Nanchang University, China. He is currently an Assistant Professor of Management Science and Engineering in College of Economics and Management at Nanjing University of Aeronautics and Astronautics. His research interests include process optimization, design of experiments, and ensemble modeling.

Jai-Hyun Byun is a Professor of Industrial and Systems Engineering at Gyeongsang National University, Korea. He received his BS in Industrial Engineering from Seoul National University and both MS and $\mathrm{PhD}$ in Industrial Engineering from Korea Advanced Institute of Science and Technology, Korea. He is currently a Vice President of the Korean Society for Quality Management. His main research interest is in the field of quality management and engineering and design of experiments. 